\title{
O mundo da urticária, com e sem alergia
}

Marta Chambel,* João Antunes, ${ }^{*}$ Sara Prates**

\section{RESUMO}

A urticária é uma entidade clínica comum a um grupo heterogéneo de doenças, devendo ser entendida como um sintoma e não como uma doença. As lesões cutâneas características são pápulas eritematosas ou com zona central pálida e eritema circundante, pruriginosas, que desaparecem à digitopressão e regridem completamente em menos de 24 horas. Embora na maioria dos casos se apresente de forma isolada, pode acompanhar-se de angioedema.

A urticária pode atingir até $25 \%$ da população em qualquer momento da vida. A forma aguda (duração inferior a 6 semanas), mais frequente em crianças, é mais prevalente que a forma crónica.

Nos casos em que a etiologia é identificada, as infecções, os alimentos e os fármacos são as causas mais frequentes. As picadas de insectos e as doenças sistémicas mais raramente estão implicadas. Na urticária crónica é muito raro o envolvimento de fenómenos de alergia IgE mediada.

O recurso a exames auxiliares de diagnóstico deve ser criterioso e sustentado por dados clínicos relevantes, não sendo recomendável a requisição de avaliações analíticas exaustivas.

Na sua maioria, os episódios de urticária são de curta duração e resolução espontânea. A urticária aguda tem uma duração média de 7 dias; já a forma crónica tem uma evolução muito variável.

No que respeita à terapêutica, a eliminação do agente causal é a abordagem ideal, embora nem sempre possível. O tratamento sintomático de eleição são os antihistamínicos $\mathrm{H} 1$ não sedativos, em dosagem superior à habitualmente recomendada. Terapêuticas alternativas podem associar-se a estes fármacos, embora não existam fortes evidências científicas que comprovem a sua eficácia.

Em algumas situações é importante referenciar a consulta especializada (Dermatologia ou Imunoalergologia); são exemplo as situações IgE mediadas (alergia alimentar ou medicamentosa), ausência de resposta à terapêutica optimizada ou alterações sugestivas de doença sistémica.

Palavras-chave: Urticária; Angioedema; Prurido; Alergia; Antagonistas da Histamina.

\section{DEFINIÇÃO}

A urticária é uma entidade clínica comum a um grupo heterogéneo de doenças e que se caracteriza pelo aparecimento súbito de lesões cutâneas características, podendo acompanhar-se de angioedema. Deve ser entendida como um sintoma, e não como uma doença.

A designação de urticária é, por vezes, aplicada de forma indiscriminada e pouco rigorosa, a diferentes tipos de lesões cutâneas, conduzindo assim a erros diag-

*Interno do Internato Médico de Imunoalergologia, Serviço de Imunoalergologia, Hospital Dona Estefânia - Centro Hospitalar de Lisboa Central.

**Assistente Hospitalar de Imunoalergologia, Serviço de Imunoalergologia, Hospital Dona Estefânia - Centro Hospitalar de Lisboa Central. nósticos e terapêuticos desnecessários. Importa então, apontar os critérios clínicos que permitem reconhecer urticária, em rigor.

Tipicamente, as lesões urticariformes são pápulas eritematosas ou com zona central pálida e eritema circundante, bem delimitadas, pruriginosas (ou com sensação de picada), que desaparecem à digitopressão, com regressão completa de cada lesão em menos de 24 horas, sem lesão residual e por vezes com recrudescência das lesões noutras localizações. A dimensão é variável, podendo confluir e atingir grandes dimensões. Podem acompanhar-se de angioedema - edema do tecido celular subcutâneo, que com frequência apresenta um carácter mais doloroso do que pruriginoso e que pode durar até 72 horas. No entanto, na maioria dos ca- 
sos, a urticária apresenta-se de forma isolada, sem angioedema (cerca de $85 \%$ versus $9 \%$ ). ${ }^{1-3}$

A célula efectora principal na urticária é o mastócito, cuja activação leva à libertação de histamina que é o mediador major na urticária. Outras substâncias vasoactivas, como os leucotrienos e prostaglandinas, são também intervenientes neste processo, contribuindo para as fases inicial e tardia da urticária. As substâncias libertas pelo mastócito induzem vasodilatação a nível cutâneo, com aumento do fluxo sanguíneo e permeabilidade vascular locais. Os factores que induzem a activação/desgranulação do mastócito são variados, e incluem ligação de alergénios ou autoanticorpos a IgE presentes na superfície da célula; interferência no metabolismo do ácido araquidónico; activação do sistema do complemento por agentes infecciosos ou autoanticorpos. $^{1}$

\section{CLASSIFICAÇÃO}

Em 2009 foi revista a classificação de urticária (Quadro I). ${ }^{1}$ Consideram-se globalmente três grandes grupos, de acordo com as características clínicas e o tipo de factor desencadeante: urticária espontânea; urticária física; uma terceira classe que inclui diversos tipos de urticária com especificidades próprias.

É importante referir que, no mesmo doente, pode coexistir mais de um tipo de urticária, como por exemplo a presença de urticária física associada a lesões espontâneas (idiopáticas).

Define-se como urticária aguda aquela que dura menos de 6 semanas e crónica a de duração superior. Em alguns casos, o doente tem vários episódios, cada um com duração inferior a 6 semanas; estes designam-se por urticária crónica recorrente. As formas agudas são mais frequentes que as crónicas, atingindo até $25 \%$ da população em algum momento da sua vida. A incidência é maior em crianças e adultos jovens, enquanto as formas crónicas afectam sobretudo indivíduos > 40 anos, com predomínio no sexo feminino. ${ }^{4}$

\section{CAUSAS DE URTICÁRIA}

De acordo com os dados da literatura, a percentagem de casos de urticária, aguda ou crónica, em que a etiologia é identificada é, por diversos motivos, variável, podendo oscilar entre 40 e $90 \% .^{1,5}$

Nos doentes em que a causa é identificada, as infecções são, em qualquer faixa etária, o principal agente etiológico implicado. Seguem-se os alimentos, fármacos e, em situações mais raras, picada de insectos (por serem mais raras não são focadas neste documento), nomeadamente os himenópteros. Na urticária crónica é muito raro o envolvimento de fenómenos de alergia IgE mediada.

\section{Infecções}

Relativamente às causas infecciosas, os mecanismos fisiopatológicos são ainda pouco conhecidos e nem sempre é fácil o estabelecimento da relação causal entre urticária e infecção. Múltiplos agentes virais, bacterianos ou parasitários têm sido implicados. Cerca de 40$50 \%$ dos casos de urticária aguda são atribuídos a in-

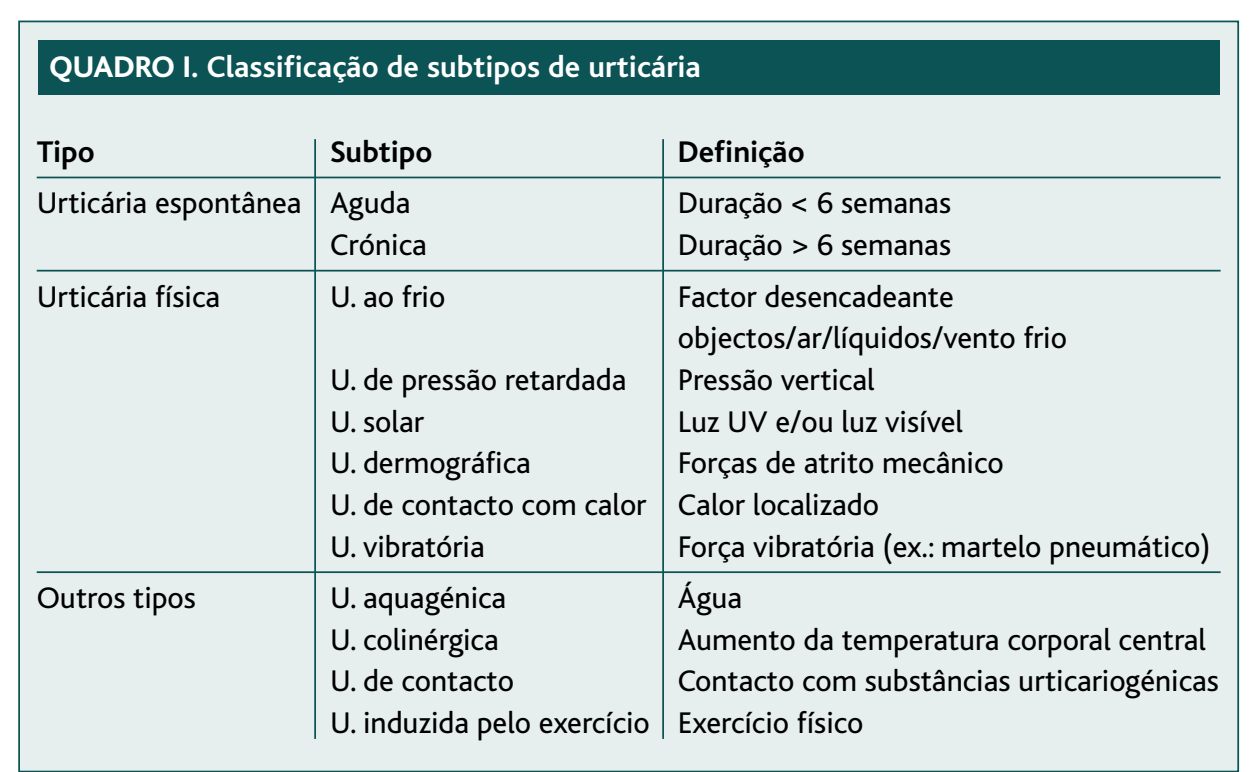

Legenda: U: urticária 
fecções, sendo as virais respiratórias e gastrointestinais as mais frequentes, sobretudo em idade pediátrica. ${ }^{6,7} \mathrm{Da}$ mesma forma, presume-se que um número significativo de casos de urticária crónica tenha, na sua origem, um processo infeccioso ${ }^{8}$, nomeadamente do foro odontológico, urinário ou otorrinolaringológico, de carácter crónico ou recidivante.

Os vírus mais frequentemente associados a urticária são o vírus Epstein-Barr, adenovírus, vírus influenza, vírus sincicial respiratório, enterovírus, citomegalovírus, parvovírus B19 e vírus da hepatite A e B. ${ }^{6,9}$

Entre os agentes bacterianos, os mais mencionados são estreptococos, Mycoplasma pneumoniae e Helicobacter pylori. Os parasitas mais comuns são Anisakis simplex, Giardia lamblia e Plasmodium falciparum.

O papel das infecções fúngicas permanece ainda por esclarecer. Alguns autores apontam estas infecções como possível causa de urticária aguda mas sobretudo crónica. ${ }^{6}$

\section{Alimentos}

A urticária como manifestação de reacção a alimentos pode ser alérgica (maioritariamente IgE-mediada) ou não-alérgica.

Relativamente aos casos de alergia a alimentos, a reacção pode ser desencadeada por ingestão, contacto directo com a pele ou inalação do alimento em causa (mais raro); as lesões aparecem até 1 hora após exposição ao alergénio alimentar implicado, com resolução do quadro em menos de 24 horas. Os alimentos que com maior frequência são responsáveis por reacção alérgica são as proteínas de leite de vaca, ovo, soja, trigo, pei$\mathrm{xe}$, amendoim, frutos secos e marisco e alguns frutos frescos (como o kiwi e o pêssego). A prevalência de alergia a cada um destes alimentos varia consoante a faixa etária, sendo o marisco e frutos secos mais implicados em adultos, e as proteínas de leite de vaca, trigo, soja e peixe em faixas etárias pediátricas. A urticária que surge como manifestação de alergia alimentar é geralmente uma urticária aguda. ${ }^{1,5}$

Noutros casos, a urticária pode relacionar-se com a ingestão alimentar sem que esteja em causa uma verdadeira alergia alimentar. Referimo-nos ao desencadeamento/agravamento de quadros de urticária pré-existente por alimentos que induzem libertação directa de histamina pelo mastócito (correntemente designados alimentos histamino-libertadores) e por ali- mentos ricos em aminas biogénicas ou salicilatos. Nestas situações não há mecanismos imunológicos implicados, pelo que não se consideram reacções alérgicas. São exemplos os citrinos, chocolate, morango, tomate e carne de porco, bem como os produtos de charcutaria, especiarias, queijos fermentados, álcool e enlatados. Estas reacções são dose-dependente, o início é mais tardio (6-24h após ingestão) e não existe risco de envolvimento de outros órgãos e sistemas, por oposição à «verdadeira» alergia alimentar. ${ }^{5,10}$

A urticária crónica muito raramente tem como etiologia alergia alimentar, apesar dos doentes e seus familiares com insistência, mas em vão, tentarem encontrar o alimento responsável pelo aparecimento das lesões cutâneas. Este facto muitas vezes acaba por condicionar dietas alimentares altamente restritivas, acarretando eventuais carências nutricionais e um impacto negativo na vida diária, sem qualquer benefício. No entanto, é importante não esquecer que os alimentos histamino-libertadores, embora não sejam a causa da urticária, podem condicionar o agravamento do quadro cutâneo, pelo que pode ser adequado, nalguns casos, recomendar a redução da ingesta ou evicção destes alimentos, em particular se o doente nota uma correlação consistente entre a sua ingestão e o agravamento dos sintomas.

\section{Fármacos}

Tal como na alergia alimentar, também nas reacções adversas a fármacos as manifestações mucocutâneas são as mais comuns, embora, comparativamente com a alergia a alimentos, a urticária isolada ocorra numa menor percentagem de doentes. ${ }^{11}$

Os principais factores de risco para reacção alérgica a medicamentos são o sexo feminino (à semelhança do que ocorre noutras formas de urticária), idade avançada e polimedicação. ${ }^{12,13}$ Os grupos farmacológicos que, por verdadeira alergia ou por outros mecanismos fisiopatológicos (como por exemplo interferência no metabolismo do ácido araquidónico), estão com maior frequência implicados nos quadros de urticária aguda são os anti-inflamatórios não esteróides (AINEs) e antibióticos (sobretudo betalactâmicos). ${ }^{1,5,14}$ Importa alertar para uma situação que ocorre sobretudo em idade pediátrica, com frequência geradora de dúvidas diagnósticas: o aparecimento de exantema papular após a 
administração de antibiótico. Na maioria dos casos, as manifestações cutâneas devem-se à própria infecção (exantema infeccioso), à interacção do agente infeccioso com o antibiótico em causa ou a outros fármacos administrados em simultâneo (com destaque para os AINEs). A apresentação clínica mais típica é um exantema micropapular de início tardio (por oposição a lesões de urticária com início até 1 hora após administração do fármaco), não reprodutíveis em exposições ulteriores e que não acarretam risco de envolvimento de outros órgãos ou sistemas (sobretudo respiratório ou cardiovascular). Na prática clínica, nem sempre é possível a distinção entre reacção alérgica ao fármaco e as outras situações referidas, devendo estes casos ser referenciados a consulta de Imunoalergologia. ${ }^{14,15}$

Nos casos de urticária crónica existe maior associação com anti-hipertensores [nomeadamente inibidores da enzima de conversão da angiotensina (iECAs)], diuréticos e estatinas. Estes fármacos podem não ser a causa da urticária crónica mas, à semelhança do que acontece com alguns alimentos, podem condicionar o agravamento de uma urticária crónica idiopática pré-existente. ${ }^{11,13,14}$

\section{Doença Sistémica}

Sabe-se hoje que a urticária crónica pode também estar associada a doenças sistémicas, podendo preceder em vários anos outras manifestações da doença subjacente. Neste cenário, as doenças auto-imunes, patologia da tiróide e infecções crónicas parecem assumir papel preponderante. ${ }^{16,17}$

De referir que estão descritas associações entre urticária crónica e doenças neoplásicas nomeadamente do sistema hematológico ${ }^{18-20}$, imunodeficiências primárias, nomeadamente imunodeficiência comum variável ${ }^{21}$ e outras doenças raras (criopirinopatias ou outros síndromes familiares, como a febre familiar mediterrânica), que em muito ultrapassam o âmbito desta revisão.

\section{Outras causas}

$\mathrm{Na}$ avaliação de um doente com urticária crónica, devem ser considerados os subtipos especiais de urticária e as causas físicas. A prevalência exacta da urticária física é desconhecida, variando entre 10 e 30\%. O quadro clínico é, em regra, reprodutível após exposição ao estímulo em questão (ver Quadro I), com aparecimento imediato das lesões. A excepção é a urticária de pressão retardada, em que é frequente o aparecimento de urticária muitas horas após o estímulo desencadeante..$^{22}$

Uma referência ao stress, que pode ser a única causa para episódios de urticária aguda, ou pode também ser o motivo de exacerbação do quadro cutâneo, sobretudo nas formas crónicas. ${ }^{23,24}$

As alterações hormonais também podem ter impacto na urticária; algumas mulheres referem flutuações sintomáticas relacionadas com os ciclos menstruais. ${ }^{25}$ É durante a gravidez que algumas mulheres têm as primeiras queixas de urticária, havendo uma tendência para as mesmas recorrerem em gestações subsequentes. Esta situação justifica a referenciação da grávida a uma consulta especializada (Dermatologia e/ou Imunoalergologia). ${ }^{2}$

Quando nenhuma causa é identificada, então classifica-se como urticária espontânea (ou idiopática), aguda ou crónica, consoante o tempo de evolução. É neste grupo que se enquadram a maioria dos doentes.

\section{DIAGNÓSTICO DIFERENCIAL}

Algumas patologias podem ter apresentação clínica semelhante a urticária, fazendo parte do diagnóstico diferencial (Quadro II).

Damos particular destaque à vasculite urticariforme, não só pela sua frequência mas também porque muitas vezes é difícil distinguir as duas situações. Tipicamente, as lesões têm coloração purpúrica, duram mais de 24 horas e deixam lesão residual, além da dor poder ser o sintoma mais importante (e não o prurido, como acontece na urticária). Os sintomas sistémicos com frequência estão presentes - febre, artralgias e adenomegálias são alguns exemplos.

\section{DIAGNÓSTICO}

A causa de aparecimento das lesões é motivo de grande ansiedade para o doente e seus familiares, sendo frequente a sua atribuição a fenómenos alérgicos, 0 que nem sempre corresponde à realidade.

O esclarecimento etiológico nem sempre é possível. Na verdade, se nas formas agudas é mais fácil estabelecer a relação causal entre a doença subjacente/estímulo desencadeante e início das lesões, nas formas cró- 


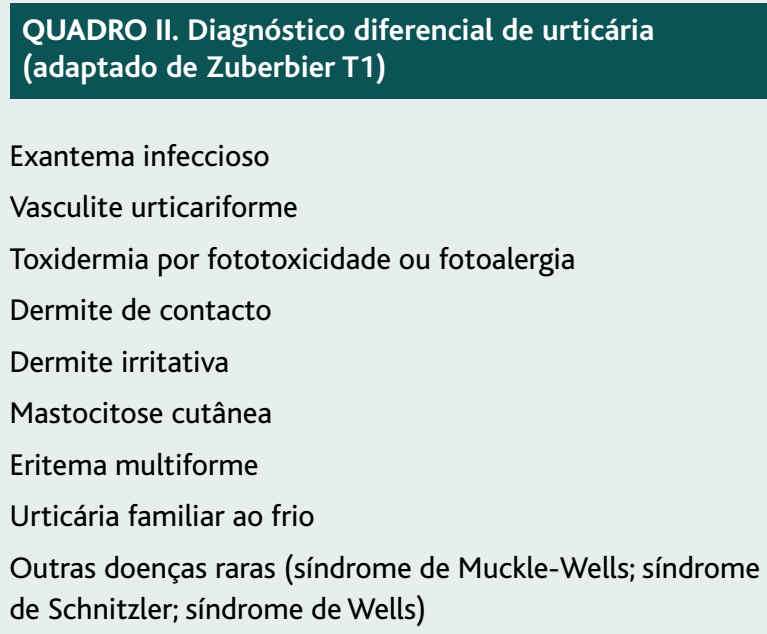

nicas apenas numa percentagem reduzida de doentes se consegue identificar a base etiopatogénica, contribuindo ainda mais para a frustração e ansiedade do doente. ${ }^{1,5}$

Importa, por isso, esclarecer aspectos fundamentais na história clínica que poderão alertar para as possíveis causas e excluir processos potencialmente mais graves ainda não diagnosticados. Podem existir também outros factores que, não sendo causa directa das lesões, contribuem para o agravamento ou desencadear das mesmas, nomeadamente alguns alimentos histaminolibertadores (citrinos, chocolate, morango, tomate, carne de porco), fármacos ou stress emocional. ${ }^{26}$

\section{História clínica e exame objectivo}

A colheita meticulosa e sistemática dos dados anamnésticos e semiológicos é indispensável ao diagnóstico médico, assumindo particular importância quando se aborda um doente com urticária. Só dessa forma será possível esclarecer, dentre os múltiplos mecanismos etiopatogénicos causais, qual o implicado no doente particular.

Deve assim inquirir-se sobre o tipo de lesão (tamanho, forma, distribuição, duração, associação com angioedema ou outros sintomas); frequência e duração das crises; relação com ingestão de alimentos (potencialmente alergénicos ou com teor elevado de aminas biogénicas), fármacos [sobretudo ácido acetilsalílico (AAS), AINES ou iECAS] e produtos ditos naturais; ex- posição a estímulos físicos (frio, vibração ou pressão directa); contacto com água; exercício físico e aumento da temperatura corporal (ex. febre); exposição ocupacional a látex ou irritantes químicos assim como actividades de lazer e domésticas que possam condicionar exposição alergénica; relação com ciclo mentrual; sinais e sintomas de doença infecciosa concomitante ou recente; identificação de distúrbios emocionais; sintomas sistémicos que possam sugerir qualquer patologia subjacente, nomeadamente doenças neoplásicas, auto-imunes ou endocrinológicas. ${ }^{27} \mathrm{~A}$ atopia, entendida como a existência de história pessoal ou familiar (pais ou irmãos) de doenças mediadas por IgE, tais como como asma, rinite alérgica ou eczema atópico, apesar de não ter qualquer implicação em casos de urticária crónica, pode assumir um papel importante na urticária aguda, sobretudo quando se suspeita de fenómenos de hipersensibilidade imediata.

\section{Quando pensar em diagnóstico diferencial de urticária?}

Quando as lesões cutâneas têm duração superior a 24-48 horas, e/ ou deixam coloração purpúrica residual, devem ser ponderados diagnósticos alternativos, sendo o mais importante a vasculite urticariforme (como já referido). Esta hipótese apenas pode ser confirmada ou excluída mediante a realização de biópsia cutânea, pelo que os doentes nesta situação devem ser encaminhados para consulta de Dermatologia ou Imunoalergologia.

\section{Exames auxiliares de diagnóstico}

O recurso a exames auxiliares de diagnóstico, que visam a identificação da causa da urticária, deve ser criterioso e sustentado por dados clínicos relevantes, procurando assim evitar-se exames desnecessários que apenas agravam a ansiedade do doente, além dos encargos onerosos que acarretam.

Na urticária aguda os exames solicitados visam essencialmente a confirmação de processos infecciosos ou de fenómenos de hipersensibilidade imediata (IgE-mediada), cuja realização deve ser feita sempre em função da suspeita clínica, conforme as boas práticas médicas.

No primeiro caso, podem requisitar-se serologias virais, exames culturais ou bacteriológicos. Destacam-se a serologia de vírus Epstein-Barr, hepatite A e B, bem como a pesquisa de estreptococos do grupo A na oro- 
faringe. Quanto aos casos em que há suspeita de alergia alimentar IgE-mediada, o diagnóstico é feito por testes cutâneos por picada e/ou pesquisa de IgE específicas no soro para o alergénio em questão. ${ }^{1,5,25}$ Estes métodos podem apresentar resultados falsamente positivos, devendo ser efectuados apenas quando existe uma suspeita sólida-quadro de urticária reprodutível, que ocorre sempre que há contacto com o alimento, aparecendo as lesões até uma hora após exposição ao alergénio alimentar implicado e havendo resolução do quadro em menos de 24 horas.

Quanto à alergia a fármacos, os testes diagnósticos in vivo e in vitro apresentam sérias limitações, nomeadamente no que respeita à sua sensibilidade e especificidade. Desta forma, quando a história clínica é altamente sugestiva de uma verdadeira alergia medicamentosa, o doente deve também ser referenciado a consulta de Imunoalergologia, para eventual realização de testes cutâneos e/ou prova de provocação, com o fármaco implicado e/ou alternativo. ${ }^{11}$

Na urticária crónica, é frequente a história clínica excluir factores externos causais ou doenças subjacentes. Assim, apesar da heterogeneidade de etiologias possíveis que pode levar o clínico a requisitar avaliações analíticas exaustivas, estas não são recomendáveis, não só pelos custos que acarretam sem benefício adicional, mas também pelo risco de, ao pesquisar «tudo»" sem critério, poderem surgir múltiplos achados sem significado clínico. No Quadro III está indicada a avaliação complementar a requisitar em cada tipo de urticária. Alguns dos exames complementares estão indicados a título informativo, na medida em que devem ser realizados em consulta de Imunoalergologia; é o caso do teste de soro autólogo, provas de provocação com agentes físicos e biópsia cutânea.

\section{EVOLUÇÃO}

A maioria dos episódios de urticária são de curta duração e resolução espontânea, ao fim de um tempo de duração variável.

A urticária aguda tem uma duração média de 7 dias, estimando-se no entanto que até $30 \%$ das formas agudas poderão progredir para quadros crónicos. ${ }^{2,25}$

A evolução das formas crónicas é muito variável e não existem marcadores clínicos ou laboratoriais que possam prever a duração do quadro. Alguns dados apontam para a remissão dos sintomas em quase metade dos doentes ao fim de 1 ano. ${ }^{28}$ Pode haver persistência dos sintomas por mais de 5 anos em quase $12 \%$ dos casos. ${ }^{4}$ Relativamente à recorrência da urticária, não existem estudos prospectivos com duração suficiente que permitam determinar a probabilidade de recorrência após resolução completa das queixas.

\section{TERAPÊUTICA}

Apesar da heterogeneidade de causas que podem manifestar-se por urticária, existem três linhas de abordagem: 1) medidas gerais; 2) identificação e eliminação do factor causal e/ ou estímulo desencadeante ou agravante; 3) tratamento sintomático.

\section{Medidas gerais}

Assumem particular importância no doente com urticária crónica.

\subsection{Evicção de fármacos}

A evicção de IECAs, AAS e outros AINEs, opiáceos e beta-bloqueantes pode facilitar o controlo clínico, na medida em que são fármacos que interferem com mecanismos favorecedores do aparecimento de urticária. ${ }^{29}$ A decisão de evitar alguns destes fámacos deve ser ponderada em função da relação risco-benefício.

\subsection{Restrição da ingestão de alimentos ricos em ami- nas biogénicas ou salicilatos}

Conforme já referido, dos alimentos que podem desencadear/agravar as crises de urticária destacam-se os citrinos, carne de porco, tomate, chocolate, morango, produtos de charcutaria, especiarias, queijos fermentados, álcool e enlatados. Embora a dieta dos doentes com urticária deva basear-se em alimentos com a menor manipulação industrial possível, o clínico não deve cair no erro de instituir um dieta altamente restritiva, que geralmente não é benéfica, além de não existir evidência científica que o justifique. A necessidade, a amplitude e o benefício da restrição dietética devem ser avaliados caso a caso. ${ }^{12}$

\subsection{Gestão de stress}

Embora os distúrbios psicoemocionais e o stress não sejam a causa, por si só, de urticária, são reconhecidos factores agravantes. Tem sido demonstrada a utilidade 
de intervenção psicológi$\mathrm{ca}^{30-32}$ nomeadamente identificação de acções e pensamentos que agravem o quadro, com subsequente ensino de como lidar com essas situações.

Também as técnicas de relaxamento são uma arma terapêutica útil para lidar com os sintomas, bem como para diminuir a frequência e intensidade das crises. ${ }^{30,31}$

\section{Identificação e elimi- nação do factor causal e/ou estímulo desen- cadeante}

Esta é a abordagem terapêutica ideal, mas nem sempre possível. Quando identificada a presença de um agente infeccioso, o tratamento dirigido pode condicionar uma melhoria do quadro clínico. Destacam-se as infecções bacterianas da nasofaringe, parasitárias intestinais e a H.pilory. ${ }^{6,33,34}$ Relativamente à alergia a alimentos e fármacos, após ter um diagnóstico de certeza (ou elevada suspeição clínica, no intervalo de tempo que medeia entre o episódio de urticária e o resultado dos exames complementares), a evicção do alergénio é a recomendação mais importante. Já na urticária crónica idiopática em que existe suspeita de agravamento por determinados alimentos e/ou medicamentos, a sua evicção está também indicada, na medida em que, embora não resolva completamente a urticária, pode atenuar a intensidade das queixas.

\section{Tratamento sintomático}

Os fármacos a prescrever para alívio de sintomas variam consoante seja um quadro de urticária aguda ou crónica. A terapêutica de eleição é, em ambas as situações, o antihistamínico (AH) H1, devendo a escolha do clínico recair sempre sobre um antihistaminico de segunda geração, não sedativo; os antihistamínicos de primeira geração, pelo seu marcado efeito sedativo sem efeito antipruriginoso adicional, não estão recomendados. ${ }^{1}$ Podem apenas ter algum papel nos doentes em que o prurido nocturno tenha implicações importantes na qualidade do sono. ${ }^{35}$ De referir que as moléculas mais recentes, embora muito diferentes dos $\mathrm{AH} \mathrm{H1}$ de $1^{\text {a }}$ geração, podem ter algum efeito sedativo, sobretudo com doses elevadas. A fexofenadina e a desloratadina são as moléculas em que esse efeito é menos marcado. ${ }^{36,37}$

Uma vez que a abordagem farmacológica subsequente não é semelhante para as duas situações, optamos por focar em separado a urticária aguda e crónica.

\subsection{Urticária aguda}

\subsubsection{MEDICAÇÃO DE 1. a LINHA - ANTIHISTAMÍnICOS H1}

A dose pode ser duplicada caso não exista melhoria 
das queixas. As orientações do último consenso europeu ${ }^{1}$ apontam para a possibilidade de quadruplicar a dose diária quando não há controlo dos sintomas, ${ }^{1,38,39}$ embora alguns autores não tenham encontrado benefício com doses tão elevadas. ${ }^{36,40}$ Também não é consensual se a toma deve ser única ou dividida em duas tomas diárias.

Na criança existe também indicação de que é seguro quadruplicar a dose diária, não esquecendo o ajuste ao peso corporal.

Quando não há melhoria do quadro com um AH H1, em dose optimizada, é lícito tentar o controlo da doença associando outro fármaco do mesmo grupo. Embora não haja estudos controlados, muitos clínicos têm defendido que a associação de duas ou mais moléculas, cada uma delas na dose recomendada, é mais eficaz no controlo das queixas. Não existem, no entanto, estudos que demonstrem se existe alguma associação mais eficaz no controlo das queixas.

\subsubsection{MEdicaÇão de 2. ${ }^{a}$ LINHA - CoRTICOSTERóide SISTÉMICO}

Estes fármacos devem ser prescritos sempre em associação a AH H1. Estão indicados quando as lesões são exuberantes e/ou generalizadas, atingindo grande parte da superfície corporal, quando o quadro se acompanha de angioedema ou quando não existe melhoria com AH H1 isolado (em dose óptima). Deve ser prescrita uma dose diária de 1-1,5mg/Kg de prednisolona (ou equivalente) até um máximo de $60 \mathrm{mg} /$ dia, dividido em duas tomas, devendo o tratamento ser mantido por cinco dias. ${ }^{41}$ Apesar de não ter sido demonstrado que deve ser feita redução progressiva da corticoterapia, parece haver risco de recorrência das queixas quando estes fármacos são interrompidos abruptamente. Assim, pode ser benéfico fazer desmame desta medicação.

\subsection{Urticária crónica}

\subsubsection{MEdiCAÇão DE 1. ${ }^{a}$ LINHA - ANTIHISTAMÍNICOS H1}

É esperado que ocorra melhoria das queixas até 4 semanas após início da medicação. Caso isto não se verifique, o clínico deve ponderar associar terapêutica de 2. ${ }^{a}$ linha.

\subsubsection{MEdicaÇão DE SEGUNDA LINHA}

a) Corticosteróide sistémico-podem ter utilidade em exacerbações, quando prescritos por curtos períodos, reduzindo a duração do episódio. ${ }^{[4]}$ A sua prescrição nas agudizações deve ser ponderada na medida em que, após a sua suspensão, o efeito rebound pode ocorrer, tornando a sua utilização mais frequentemente necessária, com intervalos menores entre cada prescrição. O esquema proposto, quando fundamental a sua utilização, é de 0,5-1 mg/Kg peso, em dose única matinal, até à completa resolução sintomática, com redução progressiva em 10-15 dias. ${ }^{42}$ A utilização a longo prazo deve ser evitada, não só pelos seus sobejamente conhecidos efeitos secundários mas também pela possibilidade de haver desenvolvimento de tolerância com necessidade de doses progressivamente maiores.

b) Antihistamínicos $\mathbf{H}_{2}$ - Um pequeno número de estudos demonstrou a eficácia desta classe de fármacos (até $300 \mathrm{mg} / \mathrm{dia}$ ), reduzindo a duração das queixas. ${ }^{1,12,29,43-46}$

c) Antidepressivo tricíclicos - São eficazes sobretudo em casos de urticária retardada de pressão. ${ }^{47-50} \mathrm{~A}$ mirtazapina deve ser prescrita numa dose diária de $30 \mathrm{mg}$. É preconizada a utilização de doxepina (não comercializada em Portugal) na dose de 10-30mg/dia (dose única, à noite)

d) Antagonista dos receptores de leucotrienos (montelucaste)- deve ser empregue sempre em associação a AH H1. A sua utilidade está clinicamente comprovada, sobretudo em doentes com hipersensibilidade a AINEs, casos de urticária retardada de pressão e casos muito particulares de urticária autoimune. ${ }^{51,52}$

\subsubsection{MEDiCAÇÃo aLTERNATIVA}

Não existem estudos controlados com estes fármacos em doentes com urticária. Assim, a sua prescrição deve limitar-se a situações refractárias a todas as opções terapêuticas anteriormente referidas, e como tal em consulta diferenciada (Dermatologia ou Imunoalergologia). Deve ser sempre considerando o risco/benefício da sua utilização. ${ }^{5,53,54}$

a) Ciclosporina: conjuntamente com $\mathrm{AH} H 1$, é a única classe de fármacos em que o nível de evidência da sua utilização é elevado. Está preconizada a sua prescrição em doses diárias de 2,5-5mg/Kg, associada a AH H1, sempre acompanhada de monitorização de 
função renal, hepática, perfil lipídico e tensão arterial, e não esquecendo o risco infeccioso a que estes doentes ficam sujeitos.

b) A utilização de dapsona, colchicina, hidroxicloroquina, cetotifeno, danazol, sulfassalazina tem sido referida mas não existe nível de evidência suficiente a suportá-la.

c) Metotrexato, ciclofosfamifa, micofenolato de mofetil, tacrolimus têm sido referidos em estudos não controlados, com pequenas amostras ou em casos clínicos isolados.

\section{TERAPÊUTICA - SITUAÇÕES PARTICULARES}

\section{Gravidez e amamentação, lactente e idoso}

O uso de medicação sistémica deve ser evitado, sobretudo, no primeiro trimestre de gravidez. Existe apenas uma meta-análise, feita com loratadina, em que foi demonstrada a ausência de efeito prejudicial sobre o feto. ${ }^{55}$ Por este motivo, esta deve ser a opção na grávida, embora o aumento da dose deva ser feito com cautela dada a ausência de estudos que comprovem a segurança desta medida.

Na mulher a amamentar, a cetirizina, a par com a loratadina, parece também ser segura.

No lactente é preconizada a utilização de hidroxizina, dimetindeno e difenidramina, na medida em que os AH H1 de segunda geração estão aprovados para utilização apenas acima dos 6 meses de idade.

O idoso constitui um grupo muito particular, não só pela polimedicação, mas também pelas comorbilidades multissistémicas presentes. Assim, deverão escolher-se os fármacos com menor interferência nos esquemas de tratamento previamente usados. Os AH H1 com os quais não estão descritas interacções com outros fármacos são a clemastina, dimentideno, cetirizina, desloratadina, fexofenadina e loratadina. Outro aspecto a ter em conta na escolha desta classe de fármacos é a via de eliminação e metabolização; deve ser dada especial atenção e avaliada a função renal. Os AH H1 que parecem ser mais seguros na insuficiência renal, por não haver referência à necessidade de ajuste da dose, são a ebastina e fexofenadina.

\section{Quando referenciar a consulta de Imunoalergologia?}

Consideramos importante a referenciação a consulta desta especialidade sempre que haja dúvidas relati- vamente ao diagnóstico ou terapêutica e nas situações que exijam a realização de exames complementares de diagnóstico ou uma abordagem terapêutica especializada, como as que se referem abaixo:

- História clínica de alergia IgE-mediada (alimentar ou medicamentosa)

- Urticária física

- Urticária generalizada após picada de insectos (nomeadamente abelha e vespa), em especial se associada a outros sintomas sistémicos (gastrointestinais; respiratório - dificuldade respiratória obstrutiva baixa, edema laríngeo; cardiovasculares - hipotensão, perda de conhecimento, sensação de desmaio)

- Vasculite urticariforme

- Ausência de resposta a terapêutica com antihistamínicos H1 e corticóide sistémico, em dose optimizada (seja urticária aguda ou crónica)

- Alterações analíticas sugestivas de doença sistémica

\section{REFERÊNCIAS BIBLIOGRÁFICAS}

1. Zuberbier T, Asero R, Brindslev-Jensen C, Walter Canonica G, Church MK, Giménez-Arnau AM, et al. EAACI/GA2LEN/EDF/WAO guideline: definition, classification and diagnosis of urticaria. Allergy 2009 Oct; 64 (10): 1417-26.

2. Champion RH, Roberts SO, Carpenter RG, Roger JH. Urticaria and angio-oedema: a review of 554 patients. Br J Dermatol 1969 Aug; 81 (8): 588-97.

3. Zuberbier T, Iffländer J, Semmler C, Henz BM. Acute urticaria: clinical aspects and therapeutic responsiveness. Acta Dermat Venereol 1996 Jul; 76 (4): 295-7.

4. Gaig P, Olona M, Muñoz Lejarazu D, Caballero MT, Domínguez FJ, Echechipia S, et al. Epidemiology of urticaria in Spain. J Investig Allergol Clin Immunol 2004; 14 (3): 214-20.

5. Kaplan AP. Urticaria and angioedema. In: Adkinson NF, Bochner BS, Busse WW, Holgate ST, Lemanske RF, Simons ER, editors. Allergy Principles and Practice. 7th ed. Philadelphia, PA: Mosby/Elsevier; 2008. p. 1063-82.

6. Wedi B, Raap U, Wieczorek D, Kapp A. Urticaria and infections. Allergy Asthma Clin Immunol 2009 Dec; 5 (1): 10.

7. Ribeiro L. Urticária aguda: infecções. In: Pereira C, editor. Urticária Imunopatologia, clínica e terapêutica. Lisboa: Permanyer Portugal, 2001. p. 113-6.

8. Sackesen C, Sekerel BE, Orhan F, Kocabas CN, Tuncer A, Adalioglu G. The etiology of different forms of urticaria in childhood. Pediatr Dermatol 2004 Mar-Apr; 21 (2): 102-8.

9. Huang SW, Borum PR. Study of skin rashes after antibiotic use in young children. Clin Pediatr 1998 Oct; 37 (10): 601-7.

10. Santa-Marta C. Urticária aguda. In: Pereira C, editor. Urticária da clínica à terapêutica. Lisboa: MSD; 2010. p. 55-76. 
11. Faria E. Urticária aguda: fármacos. In: Pereira C, editor. Urticária Imunopatologia, clínica e terapêutica. Lisboa: Permanyer Portugal; 2001. p. 87-101.

12. Poonawalla T, Kelly B. Urticaria: a review. Am J Clin Dermatol 2009; 10 (1): 9-21.

13. Alam R, Gorska M. Lymphocytes. J Allergy Clin Immunol 2003 Feb; 111 (2 Suppl): S476-85.

14. Grattan CE. Aspirin sensitivity and urticaria. Clin Exp Dermatol 2003 Mar; 28 (2): 87-101.

15. Ricci G, Giannetti A, Belotti T, Dondi A, Bendandi B, Cipriani F, et al. Allergy is not the main trigger of urticaria in children referred to the emergency room. J Eur Acad Dermatol Venereol 2010 Nov; 24 (11): 13478.

16. Pereia C, Todo-Bom A, Julião MJ, et al. Fenotipagem linfocitária na vasculite urticariana. Rev Port Imunoalergologia 1995; 3: 77-83.

17. Kaplan AP, Greaves M. Pathogenesis of chronic urticaria. Clin Exp Allergy 2009 Jun; 39 (6): 777-87.

18. Kasperska-ZajacA, Brzoza Z, Rogala B. Dehydroepiandrosterone and dehydroepiandrosterone sulphate in atopic allergy and chronic urticaria. Inflammation 2008 Jun; 31 (3): 141-5.

19. Jamison SC, Brierre S, Sweet J, de Boisblanc B.A case of precocious emphysema and lung cancer in a woman with a history of hypocomplementemic urticarial vasculitis. Chest 2008 Mar; 133 (3): 787-9.

20. Dibbern DA Jr, Dreskin SC. Urticaria and angioedema: an overview. Immunol Allergy Clin North Am 2004 May; 24 (2): 141-62.

21. Smith AA, Humphrey J, McAuley JB, Tharp MD. Common variable immunodeficiency presenting as chronic urticaria. J Am Acad Dermatol 2008 Aug; 59 (2Suppl 1): 40-1.

22. Morais Almeida M. Urticária física. In: Pereira C, editor. Urticária da clínica à terapêutica. Lisboa: MSD; 2010. p. 177-207.

23. Arck P, Paus R. From the brain-skin connection: the neuroendocrineimmune misalliance of stress and itch. Neuroimmunomodulation 2006; 13 (5-6): 347-56.

24. Marques-DeakA, Cizza G, Sternberg EM. Brain-immune interactions and disease susceptibility. Mol Psychiatry 2005 Mar; 10 (3): 239-50.

25. Deacock SJ.An approach to the patient with urticaria. Clin Exp Immunol 2008 Aug; 153 (2): 151-61.

26. Maurer M, Grabbe J. Urticaria: its history-based diagnosis and etiologically oriented treatment. Dtsch Arztebl Int 2008 Jun; 105 (25) 45865.

27. Pereira C. Clínica e classificação da urticária. In: Pereira C, editor. Urticária da clínica à terapêutica. Lisboa: MSD; 2010. p. 37-56.

28. Kozel MM, Mekkes JR, Bossuyt PM, Bos JD. Natural course of physical and chronic urticaria and angioedema in 220 patients. J Am Acad Dermatol 2001 Sep; 45 (3): 387-9.

29. Najib U, Sheikh J. The spectrum of chronic urticaria. Allergy Asthma Proc 2009 Jan-Feb; 30 (1): 1-10.

30. Gatchel R, Baum A. An introduction to health psychology. New York: Random House; 1983.

31. France R, Robson M. Cognitive behavioural therapy in primary care: a practical guide. London: Jessica Kingsley Publishers; 1995.

32. DECO Proteste. Prevenir e tratar as alergias. Lisboa: DECO Proteste; 2005.

33. Wedi B, Raap U, Kapp A. Chronic urticaria and infections. Curr Opin Al- lergy Clin Immunol 2004 Oct; 4 (5): 387-96.

34. Wedi B, Kapp A. Helicobacter pylori in skin diseases: a critical appraisal. Am J Clin Dermatol 2002; 3 (4): 273-82.

35. Kaplan AP. What the first 10.000 patients with chronic urticaria have taught me: a personal journey. J Allergy Clin Immunol 2009 Mar; 123 (3): 713-7.

36. Kaplan AP, Spector SL, Meeves S, Liao Y, Varghese ST, Georges G. Oncedaily fexofenadine treatment for chronic idiopathic urticaria: a multicenter, randomized, double-blind, placebo-controlled study. Ann Allergy Asthma Immunol 2005 Jun; 94 (6): 662-9.

37. Augustin M, Ehrle S. Safety and efficacy of desloratadine in chronic idiopathic urticaria in clinical practice: an observational study of 9246 patients. J Eur Acad Dermatol Venereol 2009 Mar; 23 (3): 292-9.

38. Zuberbier T, Münzberger C, Haustein U, Trippas E, Burtin B, Mariz SD, et al. Double-blind crossover study of high-dose cetirizine in cholinergic urticaria. Dermatology 1996; 193 (4): 324-7.

39. Kontou-Fili K, Maniatakou G, Demaka P, Paleologos G. Therapeutic effect of cetirizine $2 \mathrm{HCl}$ in delayed pressure urticaria. Health Sci Rev 1989; 3: 23-5.

40. Asero R. Chronic unremitting urticaria: is the use of antihistamines above the licensed dose effective? A preliminary study of cetirizine at licensed and above-licensed doses. Clin Exp Dermatol 2007 Jan; 32 (1): 34-8.

41. Zuberbier T, Iffländer J, Semmler C, Henz BM. Acute urticaria: clinical aspects and therapeutic responsiveness. Acta Derm Venereol 1996 Jul; 76 (4): 295-7.

42. Chieira L. Uricária crónica recorrente. In: Pereira C, editor. Urticária Imunopatologia, clínica e terapêutica. Lisboa: Permanyer Publicações; 2001. p. 135-45.

43. Bleehen SS, Thomas SE, Greaves MW, Newton J, Kennedy CT, Hindley $\mathrm{F}$, et al. Cimetidine and chlorpheniramine in the treatment of chronic idiopathic urticaria: a multi-centre randomized double-blind study. $\mathrm{Br}$ J Dermatol 1987 Jul; 117 (1): 81-8.

44. Diller $\mathrm{G}$, Orfanos $\mathrm{CE}$. Behandlung der idiopathischen Urticaria mit $\mathrm{H} 1$ $+\mathrm{H}$ 2-Antagonisten. Ergebnisse einer Crossover-Doppelblind-Langzeitstudie. Z Hautkr 1983 Jun 1; 58 (11): 785-93.

45. Harvey RP, Wegs J, Schocket AL. A controlled trial of therapy in chronic urticaria. J Allergy Clin Immunol 1981 Oct; 68 (4): 262-6.

46. Monroe EW, Cohen SH, Kalbfleisch J, Schulz Cl. Combined $\mathrm{H} 1$ and $\mathrm{H} 2$ antihistamine therapy in chronic urticaria. Arch Dermatol 1981 Jul; 117 (7): 404-7.

47. Goldsobel AB, Rohr AS, Siegel SC, Spector SL, Katz RM, Rachelefsky GS, et al. Efficacy of doxepin in the treatment of chronic idiopathic urticaria. J Allergy Clin Immunol 1986 Nov; 78 (5 Pt 1): 867-73.

48. Greene SL, Reed CE, Schroeter AL. Double-blind crossover study comparing doxepin with diphenhydramine for the treatment of chronic urticaria. J Am Acad Dermatol 1985 Apr; 12 (4): 669-75.

49. Harto A, Sendagorta E, Ledo A. Doxepin in the treatment of chronic urticaria. Dermatologica 1985; 170 (2): 90-3.

50. Thormann $\mathrm{H}$, Bindslev-Jensen C. Mirtazapine for chronic urticaria. Acta Derm Venerol 2004; 84 (6): 482-3.

51. Powell RJ, Du Toit GL, Siddique N, Leech SC, Dixon TA, Clark AT, et al.; British Society for Allergy and Clinical Immunology (BSACI). BSACI guidelines for the management of chronic urticaria and angio-oede- 
ma. Clin Exp Allergy 2007 May; 37 (5): 631-50.

52. Erbagci Z. The leukotriene receptor antagonist montelukast in the treatment of chronic idiopathic urticaria: a single-blind, placebo-controlled, crossover clinical study. J Allergy Clin Immunol 2002 Sep; 110 (3): 4848.

53. Kozel MM, Sabroe RA. Chronic urticaria: aetiology, management and current and future treatment options. Drugs 2004; 64 (22): 2515-36.

54. Cassano N, D'Argento V, Filotico R, Vena GA. Low-dose dapsone in chronic idiopathic urticaria: preliminary results of an open study. Acta Derm Venereol 2005;85 (3): 254-5.

55. Schwarz EB, Moretti ME, Nayak S, Koren G. Risk of hypospadias in offspring of women using loratadine during pregnancy: a systematic review and meta-analysis. Drug Saf 2008; 31 (9): 775-8.

\section{CONFLITOS DE INTERESSE}

Os autores declaram que não têm qualquer filiação ou envolvimento financeiro em qualquer organização ou entidade com interesse financeiro directo no tema ou nos resultados discutidos neste manuscrito.

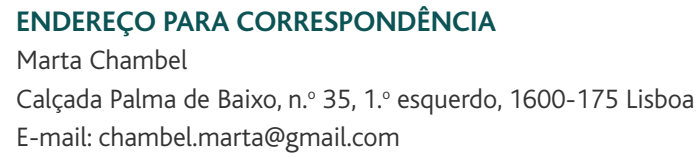

Recebido em 14/12/2010

Aceite para publicação em 14/02/2011

\section{ABSTRACT}

\section{URTICARIA'S WORLD - WITH AND WITHOUT ALLERGY}

Urticaria is a clinical entity shared by a heterogeneous group of diseases, and must be seen as a symptom and not a disease. The characteristic cutaneous lesions are erythematous papules or with a clear central zone and a peripheral erythema, pruriginous, that disappears with digital pressure and completely regresses in less than 24 hours. In some cases it's accompanied by angioedema, although usually it occurs isolated.

Urticaria may affect up to $25 \%$ of population in some moment of life. Acute urticaria (less than 6 weeks of duration), more frequent in children, is more prevalent than the chronic form.

In cases that the etiology is identified, infections, foods and medications are the most frequent causes. Insect stings and systemic diseases are more rarely involved. In chronic urticaria, allergy lgE-mediated is rare.

Complementary diagnostic exams must be criterious and supported by relevant clinical data; exhaustive analytic examinations must be avoided.

Most episodes of urticaria are of short duration and spontaneous resolution. Acute urticaria has an average duration of 7 days; the chronic form has a variable evolution.

Regarding the treatment, elimination of the causative agent is the ideal approach, but it isn't always possible. The first choice of symptomatic treatment are non sedative $\mathrm{H} 1$ antihistaminics, in higher dosage than the usually recommended. Some alternative therapeutics may be associated, but strong scientific evidence supporting their efficiency is lacking.

Referral to a specialized consultation is important in some situations; some examples are allergy IgE-mediated or suspicion of systemic disease.

Keywords: Urticaria; Angioedema; Pruritus; Hypersensitivity; Histamine H1 Antagonists. 